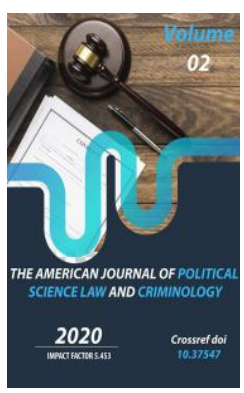

\title{
Organizational And Legal Aspects Of Digital Technologies In Counteracting Corruption
}

\author{
Bakhodir Ismailov \\ Doctor Of Law Academy Of The General Prosecutor's Office Of The Republic Of Uzbekistan
}

Copyright: Original content from this work may be used under the terms of the creative commons attributes 4.0 licence.

\section{ABSTRACT}

The article describes involvement of modern technologies in combating corruption and their actuality in the current digitalization of the world. Such ICT tools as Digital government services, Big Data Technologies, Distributed ledger technologies (DLT) and blockchain, data mining, crowdsourcing technologies, analytical (Forensic) tools and electronic systems for verification of income declarations, as well as foreign experience of their usage and implementation are thoroughly examined.

\section{KEYWORDS}

The Internet, IT-technologies, anti-corruption measures, e-government, Big Data Technologies, Distributed ledger technologies, blockchain, data mining, crowdsourcing, social credit system, highrisk transactions, transparency, conflict of interest, Artificial intelligence, fraud.

\section{INTRODUCTION}

Active involvement of the Internet and ITtechnologies in all spheres of human life and industry - from everyday life to production, characterized as the fourth wave of industrial revolution, or "Industry 4.0 " has led to rapid access to vast amounts of data about society, economy and environment. Possibilities created due to information technology tools and processing large amounts of information began to be actively used to address key problems of the state, including combating corruption. [1]

According to leading OECD researchers in the field of digitalization and anti-corruption policy, modern information technologies can significantly enhance effectiveness of ongoing 
anti-corruption measures and create a completely new ecosystem of relationships that eliminates most corruption-generating factors.

Emergence of such instruments lays great grounds and prospects for promoting anticorruption policy by radically improving the means and methods of combating corruption with analysis of causes and conditions conducive to corruption, identification, prevention, and minimization of damage from corruption crimes.

Experience of foreign countries has shown that the benefits of digitalization can only be realized if there are appropriate infrastructure, regulations, financial resources and personnel trained in ICT issues.

Depending on goals, IT technologies in the field of combating corruption can be conditionally classified into several main groups.

\section{Digital government services and e- government}

These tools have already been serving to fight corruption by expanding access to public information [2], monitoring activities of public servants, digitizing public services and ensuring reporting on corruption [3]; it is a subform of e-government that involves the use of ICTs, particularly the Internet, web devices and electronic data management systems to provide public services to citizens. [4]

An example of widespread adoption of digital public services as one of the most advanced in the world is Estonia [5] that has built digital systems for almost all public services (eEstonia).

2. Technologies for processing large amounts of data (Big Data) - a set of approaches, tools and methods for processing large amounts of structured data to obtain human-perceived results.

A very good example is the Australian Tax Office using Big Data technology to collect evidence of corruption offenses by government officials and to identify suspicious transactions in offshore zones.

In 2018, researchers from Valladolid University (Spain) created a computer model based on artificial neural networks. It calculates the likelihood of corruption in the Spanish provinces and conditions that support it.

Such terms as "social trust system", "social rating" or "social credit system" started to be widely discussed in 2014 when the State Council of the People's Republic of China released "Program for the creation of social credit system (2014-2020)" and introduced government program called "Social Trust System" (SCS)for assessing public servants. [6] The program allows for early prevention of corruption offenses according to a number of parameters and to take measures in relation to employees who attract attention of law enforcement agencies.

As of the end of April 2018, more than 15 million Chinese, that is, every hundredth resident of the country, were subject to administrative penalties due to the "low level of social rating".

\section{Distributed ledger technologies (DLT) and blockchain.}

Blockchain is used to mitigate high-risk transactions in areas that are particularly prone to corruption risks, such as property registration, land ownership and government contracting. Consequently, the use of blockchain technology can enhance transparency and prevent fraud, with possible monitoring and accountability. 
For example, German Development Bank (KfW) has been piloting a blockchain solution since 2019 to improve the transparency of budget allocations and spending in Africa. "TrnBudget" app is a platform where international financial institutions can monitor taken spending decisions and where resources been diverted. [7]

Another promising area of blockchain technology application is land registries. "Bitfury" is a privately company specializing in development of software solutions based on decentralized and synchronized data sets; the company is currently implementing a land cadaster system in Georgia using blockchain technology. The system, Bitfury explains, involves storing land ownership certificates based on a distributed ledger. [8]

The government of Shenzhen (PRC) has piloted "fintech" app, that is blockchain-based digital app developed by Tencent Technologies (WeChat). This technology aims to ensure that every account is traced, information cannot be changed and data cannot be lost. The entire process can be monitored in real time and contribute to transparency of tax regime in the country.

Every person in Estonia who visits a doctor or hospital has an electronic health record that can be tracked. Medical information identified with electronic ID card is kept safe and at the same time accessible to authorized persons.

\section{Technologies of data mining (Data Mining).}

Anti-corruption software tools such as Data Mining technology are developed specifically to detect fraud and promptly respond to its occurrence. The European Commission has partnered with Transparency International to develop similar data analysis software. This software helps to identify projects that are at risk of fraud, conflict of interest or abuse. [9]
Artificial intelligence (Al) is a type of data mining technology. Al technologies are used by countries in combating corruption and cybercrimes mainly for two tasks - automatic analysis of large amounts of data (SWIFT payments, data from social networks) and obtaining fundamentally new types of knowledge. An example is photographs facerecognition and matching them with geolocation or with social network profiles.

According to a study by CB Insights analytical company, Al companies received a record \$ 26.6 billion funding in 2,235 agreements in 2019, while in 2018 this figure was only $\$ 4.2$ billion (581 agreements). [10]

A famous precedent of the use of Al to fight against corruption is a computer system Zero Trust ("zero confidence"), developed on the basis of former Forrester analyst John Kindervaga's system in 2010.

Zero Trust system was tested in 30 counties and cities of China in 2012-2019 and assisted to identify more than 8000 violations of anticorruption prohibitions and restrictions by public servants. Zero Trust, being integrated with more than 150 protected databases, allowed analyzing antisocial behavior of employees. [11]

The system is especially useful in tracking suspicious cases of property transfers, infrastructure construction, land acquisitions and demolitions. Also, Zero Trust immediately records growth of the balance in civil servants' bank accounts and quickly establishes facts of purchase of a new car. In addition, artificial intelligence analyzes public procurement and identifies cases when officials, as well as their friends and relatives, participate in tenders.

The system then evaluates how likely it is that a particular action is the result of corruption. If the score is above the established average, the 
government is warned. If an official has tampered with some data, Zero Trust can compare information from multiple sources and find discrepancies.

Another area of Data Mining application is combating corruption in public procurement.

British authorities are also applying artificial intelligence to uncover corruption crimes. Technology called Ravn ACE was tested in 2016 in the course of investigations into British producer of aircraft engines Rolls-Royce and civil air transport division of the Airbus, employees of which were suspected of fraud, bribery and corruption.

The UK's Large Fraud Office (SFO) pioneered the Ravn ACE automated system created by a British startup to select, index and extract knowledge from documents. Using the program, seven specialists processed 600 thousand documents a day. In total, a team of seven people automatically analyzed about 30 million materials. Startup hasn't attracted funding and has about 60 customers nowadays. Ravn employs 47 people, with revenues of about $\$ 5$ million.

Palantir an American company with $\$ 20$ billion capitalization, collects data from closed and open sources, analyzes and builds dependencies based on the results, identifies anomalies and so on. Almost all law enforcement agencies and the US Army are clients of the company. They use Palantir to identify related parties, collusions, hidden alliances, fill-in data checks and others. The company is now actively expanding into commercial sector, offering services to companies in determination of financial fraud, employment related fraud etc.

In the United States, the Senate uses "eFD" (Electronic Financial Disclosure) [13], and the House of Representatives uses "Financial
Disclosure: Online Reporting". [14] The US Financial Disclosure Committee Judicial Conference uses a system called "Online Financial Disclosure". [15]

In 2012, the Office of Government Ethics (OGE), which is responsible for the development and monitoring of financial disclosure program, developed the "Integrity" system for civil servants of executive authorities. A web-based system that allows to submit public reports disclosing information about civil servants of the executive authorities, including information about new declarants, annual and periodic transactions, as well as reports after termination of powers. The system allows to improve oversight and transparency of civil servants.

\section{ICT for mining in the area of countering corruption in public procurement.}

The International Development Bank uses innovative tool of data mining for the monitoring and supervision of its activity. In government procurement, data mining is used to audit and track government bidding and subsequently to detect collusion and false information. Also, this technology identifies corrupt intentions various transactions with the use of data visualization. [16]

An example of an integrated online procurement platform is Korea's KONEPS eprocurement system. [17] In 2002, the Public Procurement Service implemented a fully integrated end-to-end e-procurement system called KONEPS. It covers the entire procurement cycle in electronic form (including one-time registration, bidding, contracting, verification and payment), with online exchange of relevant documents. All public organizations are required to announce tenders through KONEPS. [18] 
Korea Fair Trade Commission uses BRIAS (KONEPS) System which is an automated system for detecting suspicious trading strategies. The Public Procurement Service Integrity Perception Index has improved from 6.8 to 8.52 out of 10 since the launch of KONEPS, according to an Integrity Assessment by the Korea Anti-Corruption and Civil Rights Commission. A key issue for illegal practice was false electronic certificates.

To mitigate this risk, in 2010 the Public Procurement Service introduced "electronic bidding for fingerprint recognition". Introduction of a national e-procurement system has led to a noticeable increase in transparency and integrity of public procurement management in the country.

Experts from the Budapest-based Corruption Research Center examined large volumes of data on public procurement procedures in EU countries and identified risk areas such as short bidding periods or controversial results (for example, lack of competition in public procurement or multiple winning tenders). [19]

ProZorro (from Ukrainian “прозоро”| - openly, transparently), a hybrid electronic data mining system is Ukraine's systemic reform of etender process in public and government procurement. The system is developed in 2014 and administered by NGO Transparency International Ukraine. The system code is open source, according to the Apache 2.0 license, it can be freely downloaded and used.

ProZorro received international Public Sector Procurement Award for e creation and implementation of a unique-architecture electronic system. Development of this system based on open source software was carried out in partnership with government, business and public.
Another successful example of data mining usage is Dozorro (from Ukrainian “дозор”control), an online platform for public control of government tenders integrated into ProZorro databases. The platform has been implemented since November 1, 2016 and is administered by Program of Innovative Projects of "Transparency International Ukraine". The platform consolidates activities of 20 regional monitoring organizations on the quality of specific tender procedures. [20]

If a violation of the Law of Ukraine "On Public Procurement" is detected, the platform sends appeals to customers (organizers of tenders), supervisory authorities (State Audit Service, Accounts Chamber), law enforcement agencies (National Anti-Corruption Bureau of Ukraine (NABU).

\section{Crowdsourcing technologies in combating corruption.}

Crowdsourcing platforms also include digital technologies aimed at collecting and subsequent analysis of information in order to identify patterns and trends. Use of these platforms for combating corruption presupposes creation of a certain digital ecosystem, where each person has the opportunity to leave an anonymous message about a corruption offense.

Crowdsourcing platform for anti-corruption are created in the Republic of Korea (OPEN), Hungary (K Monitor), India (I Paid a Bribe), Lithuania (Manoseimas), the UK (FixMyStreet), the USA (SeeClickFix), Morocco (Mamdawrinch), Pakistan (Citizen Feedback Model), China (CCDI), Macedonia (Draw a Red Line), Romania (Bribe Market), the Philippines (Check My School), etc..[21]

Similar platforms have appeared in many countries: Yosobomo in Colombia, Toidihoilo in Vietnam, Ushahidi in Kenya. In addition, some 
anti-corruption crowdsourcing platforms focus on a specific issue, such as Nigerian Trade Route Incident Management System (TRIMS) or Check My School project in the Philippines, where citizens monitor and report on educational institutions' use of public funds.

An undoubted advantage of crowdsourcing is that it is intended to ensure interests of various social groups, create a dialogue between the state and society, and increase public control over the actions of state bodies. With the help of crowdsourcing, bills may not only be criticized by the population, but also be offered various constructive solutions to improve performance.

For example, Lithuanian Special Investigation Service (SSR) has launched a mobile application "Pranesk STT" in 2016 in order to activate reports on corruption. Mobile application was created with financial support of the EU Homeland Security Fund. [22]

7. Analytical (Forensic) tools for auditors to identify corruption risks in public and private sectors.

Self-Monitoring, Analysis and Reporting Technology (SMART) tool can be a good example of forensic tool. It carries out analysis of transactions in real-time, predicts, simulates and discovers violations in the financial sector. Risk assessment algorithms can proactively prevent and stop potentially malformed payments in the procurement process.

In Azerbaijan, electronic monitoring system [23] made it possible to collect information on digital technologies implementation level and compare contributions of NGOs to the process of combating corruption.

8. Electronic systems for verification of income declarations, expenditure, assets and interests of civil servants.
A promising direction for the use of ICT in combating corruption is electronic systems for verifying declarations of civil servants. More than 160 countries that have implemented declaration systems and about 50 countries among them have switched to electronic asset disclosure systems by August 2020 (including Argentina, Bhutan, Chile, Costa Rica, Croatia, Estonia, France, Armenia, Georgia, Indonesia, Republic of Korea, Kyrgyz Republic, Latvia Lithuania, Mexico, Moldova, Mongolia, Rwanda, Serbia, Slovenia, Uganda, Ukraine, the USA, etc.) [24]

The Republic of Korea's E-declaration system (peti.go.kr) serves as an important tool in preventing conflict of interests and illicit enrichment, increasing the integrity and rewarding responsibility of more than 1.2 million civil servants. A digital tool contributes to significant savings in manpower and resources for verification of declarations, ensures availability of data for civil society institutions, guarantees integrity of data and prevents distortion or unauthorized access to them.

High Authority for Transparency In Public Life of France developed "ARTEMIS" software for monitoring mass media in 2013. The goal of the program is to collect information from open sources about assets and economic interests of government officials.

In 2016, the High Authority developed and implemented Ulysse software to simplify and strengthen verification of declarations. The module allows to calculate deadlines for filing declarations by civil servants, taking into account the beginning of the term of office, verify data, notify law enforcement agencies about the facts of violations.

9. Electronic technologies for combating corruption in the electoral process. 
Electronic voting systems are actively developing in Great Britain, Switzerland, the USA and other countries. For example, fullscale elections using Internet resources were first held in Estonia, in 2005 the possibility of remote voting was local but by 2007 the system had acquired national scale. Voting is carried out using an Estonian citizen ID card, which is used for identification during registration. According to experts, the recorded voice is fully protected and confirmed by digital signature.

Analytical data and research on digitalization of voting confirm that digitalization of electoral process eliminates vote fraud and minimizes corruption component. Openness and transparency of electoral process makes it possible to identify violations at every stage of electoral cycle and prevent illegal actions.

Summing up, in the context of the fourth industrial revolution in a number of countries, there is a trend of active implementation of such ICTs in anti-corruption processes as technologies for processing large amounts of data, artificial intelligence, analytical analysis tools, crowdsourcing, etc.

As is shown by foreign experience, the use of modern information technologies in combating corruption provides many opportunities for innovative approach to early prevention of corruption offenses, creating a transparent and open system as public administration, rational use of budget funds, reducing negative human factor in relations between the population, business representatives and government agencies.

Effective introduction of ICT in public administration process allows to provide depersonalization and standardization of key administrative processes, to prevent corruption-related crimes, increase quality of public services and level of trust of citizens to the state. [25]

At the same time, a number of issues of both legal and ethical nature have not been resolved in this area. In particular, issues of personal data protection of civil servants, unauthorized interference in their personal life, danger of a voluntaristic and evaluative approach on the part of control and supervisory authorities, basis for groundless stigmatization of individual employees, disclosure of professional, commercial information, system and hardware failures, etc.

However, digitalization can also create new vulnerabilities for hacking and wide-scale manipulation, that are simply impossible in paper government. ICTs can also contribute to corruption. New technologies could spawn new corruption - e-corruption linked to the power of the dark web, cryptocurrencies, or simply the abuse of well-designed technologies such as digital government services.

Corruption risks of widespread use of ICT include:

- Over-investment in ICT tends to lead to increased corruption, since the distortion of such funds through an opaque procurement process easily creates corruption opportunities;

- Blockchain technology can pose a threat to anti-corruption efforts, as it allows for completely anonymous and encrypted cryptocurrency transactions that can be used for theft or fraudulent transactions;

- Electronic identity solutions are not completely secure from hackers, and governments need to continually ensure that digital solutions, platforms and systems reflect the highest security standards. This requires a regular update of technology, which can be perceived as a 
burden for both citizens and government officials.

- International standards stipulate the possibility of using high-tech tools in combating corruption in a rather generalized way.

The most promising areas of application of digital technologies: electoral process, public procurement, budgetary process, public services, land use, notaries, as well as international cooperation and communication.

ICTs influences corruption in two main ways.

Firstly, they change government's information supply to the public: ICTs deprive government officials' possibility to abuse their discretionary powers, increase oversight, and reduce transparency. However, instead of mitigating corruption, introduction of information and communication systems in the information supply arena may shift corruption into other areas of government activity and create new vulnerabilities to hacking and manipulation.

Secondly, ICTs influence on society's demand for public information by creating forms of transparency where citizens can report incidents of corruption and find platforms to share information and organize joint action. At the same time, such platforms can be used to spread false information or to help organize criminal activities.

Accordingly, in Uzbekistan, it is relevant to:

Carry out substantive study of foreign experience in the field of introducing modern technologies into the justice system, identifying positive aspects and potential risks;

Form legal basis for digitalization of judicial and law enforcement activities;

Train personnel responsible for digitalization of processes both for judicial and law enforcement agencies, as well as judges and law enforcement officers themselves in the field of using digital technologies;

Create appropriate technical infrastructure and software products;

Development of international cooperation in this area, digital interaction with foreign judicial and law enforcement agencies, etc.

\section{REFERENCES}

1. Benders J., Van Veen K. What's is in Fashion? Interpretative Viability and Management Fashions / J. Benders, K. Van Veen // Organization. 2001. Vol . 8, number 1. P. 33- 53 .

2. Lankov A.N. Modernization in East Asia [electronic resource] // "BBC News", 20104 February city of the URL : http : // polit . ru / artide / 2010/03/11 / lankov /.

3. Xiao W. Freedom of Information Reform in China: Information Flow Analysis // International Review of Administrative Sciences. 2013. V. 79. P. 790 - 808 .

4. Schuknecht C. China's war on corruption: Where is it headed? / C. Schuknecht // UCLA International Institute.

http://www.international.ucla.edu/in stitute/article/139065

5. Westney DE Imitation and Innovation: The Transfer of Western Organizational Patterns in Meiji Japan. Cambridge, MA: Harvard Univ. Press. 2000.268 p.

6. Kluver R. The Architecture of Conrol: a Chinese Strategy for E-Governance // Journal of Public Policy. 2005. V.25. No. 1. P. 75 - 97.

7. Gronlund A. Increasing transparency and fighting corruption through ICT empowering people and communities-The Swedish Program 
for ICT in Developing Regions / A. Gronlund, R. Heacock, D. Sasaki, J. Hellstrom [et al.]. (https://spidercenter.org/files/2017/01 /Spider-ICT4D-series-6-ICT-foranticorruption.pdf)

8. Drozdov I. A. Law in the digital era // Almanac "Digital Economy". M.: Skolkovo, 2017. p. 30-33.

9. Ringis A., Nefyodov L.. “Як ботаніки перемагають корупцію у держзакупівлях" (09/12/2016).

10. Truntsevsky Yu.V. Information and telecommunication technologies in the field of counteracting everyday corruption / Yu.V. Truntsevsky // Information law. 2017. N 2.P. 29.

11. Schuknecht C. China's war on corruption: Where is it headed? / C. Schuknecht // UCLA International Institute.URL: http: //www.international.ucla.edu/institut e/article/1 39065

12. Adam I. Are emerging technologies helping win the fight against corruption in developing countries? / I. Adam, M. Fazekas // Background Paper. No. 21. Oxford: United Kingdom, 2018.34 p.

13. https://efd.senate.gov

14. https://fd.house.gov.

15. https://fd.uscourts.gov

16. From products to platforms in law enforcement. Report Accenture company (USA) October 16, 2017 [Electronic resource]. - URL : https : // voicesfrompublicservice . accenture . com / unitedstates / blogs - from products - platforms - law enforcement

17. https : // www . pps . go . kr/ eng / jsp / koneps / major . eng

18. Kim K. Does Technology Against Corruption Always Lead to Benefit? I
K. Kim, T. Kang // The Potential Risks and Challenges of the Blockchain Technology. URL: https://www.oecd.org/cleangovbiz/l ntegrity-Forum-2017-Kim-Kangblockchain-technology.pdf .

19. Gronlund A. Increasing transparency and fighting corruption through ICT empowering people and communities-The Swedish Program for ICT in Developing Regions / A. Gronlund, R. Heacock, D. Sasaki, J. Hellstrom [et al.]. URL: https://spidercenter.org/files/2017/01/ Spider-ICT4D-series-6-ICT-foranticorruption.pdf.

20. Kitts D. How mobile policing technology could bring cops closer to their communities [Electronic resource]. - URL: https://tvo.org/article/currentaffairs/how-mobile-policingtechnology-could- bring-cops-closerto-their-communities

21. Ringis A. L. Nefyodov. How nerds defeat corruption in public procurement (09/12/2016).

22. UN (2003), UN Guide for AntiCorruption Policies, available at www.unodc.org/pdf/crime/corruptio n/ UN_Guide.pdf.

23. See: https: //ems.gov.az

24. Niklas Kossow, Victoria Dykes. [Embracing Digitalisation: How to use ICT to strengthen Anti-Corruption]. GIZ, $2018 . \quad$ URL: https://www.giz.de/de/downloads/gi z2018- eng ICT-to- strengthen-Anti Corrupti on.pdf.

25. See: Suleiman, MM A Review of Improving Good Governance through ICT Revitalization. 2017. URL: https://www.researchgate.net/public ation/325668385. 